Arab World English Journal (AWEJ) $2^{\text {nd }}$ Special Issue on Covid 19 Challenges January 2022 DOI: https://dx.doi.org/10.24093/awej/covid2.27

\title{
Teacher Training for Online Education in Oman: A Case Study at Two English Language Teaching Institutions
}

\author{
Osman Erdem Yapar \\ Department of English Language and Literature \\ Dhofar University, Salalah, Oman \\ Corresponding Author:: osmanyapar@du.edu.om
}

\author{
Chinthana Sandaruwan Dayananda \\ English Language Centre \\ University of Technology and Applied Sciences \\ Ibra, Oman
}

Received: $11 / 23 / 2021$

Accepted: $1 / 13 / 2022$

Published: $1 / 24 / 2022$

\begin{abstract}
This study is a joint research project carried out in two different academic institutions in Oman during the Covid-19 pandemic. The research aims to identify the perceptions of teaching faculty and administrators on the advantages and disadvantages of online education. It also explores how the training process for online teaching occurs and what support is provided afterwards. Qualitative methodology was adopted and data were collected through semi-structured interviews from a representative sample of teaching faculty and administrators from both institutions. Interview data were thematically analyzed using NVivo qualitative analysis software. Findings suggest that participants perceive more disadvantages of online education than the advantages demonstrating a rather negative perception. The training was decided mainly by administrators and focused on essential technical skills. Participants expressed a need for effective online pedagogical training. Short, practical sessions suitable for teachers at different skill and experience levels were suggested by the participants as well as informal peer support groups for continuous professional development after the training. There was some indication of administrative support in mainly infrastructure areas, which can be improved by employing specialist online education support staff. Further, peer support through formal committees or informally through colleagues was found to be accessible and practical. Findings from this study and the literature review can be used in other international contexts for effective provision of online education.
\end{abstract}

Keywords: English language teaching, online education, support, teacher training, Covid-19

Cite as: Yapar, O.E., \& Dayananda, C.S. (2022). Teacher Training for Online Education in Oman: A Case Study at Two English Language Teaching Institutions. Arab World English Journal (AWEJ) $2^{\text {nd }}$ Special Issue on Covid 19 Challenges (2) 411- 425.

DOI: https://dx.doi.org/10.24093/awej/covid2.27 


\section{Introduction}

The sudden outbreak and swift spread of the COVID-19 pandemic in 2019 disrupted aspects of everyday life and the social, political, economic and educational practices of many countries. Marinoni et al. (2020) report that, as of first April 2020, more than 3.4 billion people, or in other words, $43 \%$ of the global population, were in lockdown in more than 80 countries. The pandemic outbreak restricted many social activities, and forced people to use alternative modes and policies. The global education sector did not stop its provision but was impacted in a way that altered its usual procedures and practices. The pandemic forced educational institutions to shift from traditional classroom teaching to a blended mode and then to complete distance teaching (Andreas, 2020; Assunção Flores \& Gago, 2020; Oyadiran et al., 2020; Oyedotun, 2020). The pandemic spread across the globe and multiplied the catastrophic. The pandemic did not only affect higher educational institutions in Wuhan, China where the virus originated. Marinoni et al. (2020) highlight the enormous impact of the outbreak of the virus on higher education caused by the preventive measures against the spread of the virus, such as strict lockdown and social distancing measures. They point that the pandemic negatively affected studies and many other aspects of education. The pandemic had negative effects on scheduling assessments, academic projects, research studies and conferences. The pandemic also incurred negative financial consequences to the private education industry, as there was a decrease in student enrolment for courses. The affected areas of higher education highlighted the irreversible damage the COVID-19 has caused to the global higher education sector. As an almost compulsory reaction to the virus, the sudden transformation to online education posed many challenges to the stakeholders from developed to underdeveloped countries at different levels.

\section{Literature Review}

There are some serious advantages of online education that lead decision-makers, students, and teachers to opt for this medium of education. For example, accessibility is probably one of the most commonly considered advantages of online education both on the side of students and teachers (Ally, 2008; Berge, 1998; Chen, 2012). Online platforms also allow teaching staff to easily share materials or update them for the learners' use as and when they require (Ally, 2008; Berge, 1998).

Online education has also provided more room for independent learning for the students (Compton, 2009). Online education offers several methods for achieving new and different modes of interaction. Compton (2009) states that the developments in technology lead to increased group interaction among learners. Jacobs (2014) suggests using group projects to reduce the perceived distance in online learning. Faulkner et al. (2018) also found that discussion boards with a participation requirement provided an advantage over the face-to-face classes where only a few learners participate in discussions.

Stickler et al. (2020) discuss the disruptive and transformative nature of online education on traditional forms of language learning based on their experience at the Open University. This change brings about various new skills for the learners, such as "selecting appropriate learning materials, self-learning, self-testing, self-evaluation as well as receiving feedback from tutors" (p. 137). 
Apart from the personal benefits of online education to the learners and the teachers involved, the institutions also have some clear advantages in this medium, such as being timeand cost-effective (Berge, 1998; Compton, 2009; White 2003). These benefits are probably the driving force behind sudden shifts to online education or incorporating it into strategic plans.

\section{Challenges associated with online education}

Attitudes towards online education are a great challenge in successful implementation. A more recent study by Harton et al. (2019) found that about a third of the administrators in academic institutions reported negative attitudes of the teaching faculty as a barrier to online learning and teaching. Perceived lack of academic integrity is an example of negative attitudes towards online education. These perceptions may not necessarily be based on actual instances of cheating, though. Harton et al. (2019) found that the perception of cheating online depends on experience with online education. Students and faculty who do not have online learning/teaching experience are more likely to perceive cheating online to be more prevalent than traditional courses. On the other hand, online students reported similar perceptions of cheating in online and face-to-face courses. Therefore, he recommends working with students and faculty to improve perceptions that online education can be as academically sound and reliable as face-to-face courses (Harton et al., 2019).

A more substantial disadvantage for the teaching staff in online courses is the significant increase in the workload. Fein and Logan (2003) explain that teaching online includes a lot of extra work such as preparing for course materials, setting up the course, tasks related to the learning management system, and adjustments to the materials.

Despite significant improvements in communication technology, dependence on technology is another potential caveat of online education. The International Association of Universities (2020) counts technical infrastructure as a challenge of online education, especially in countries where the technological infrastructure for online education still needs development. Moreover, there were pedagogical challenges associated with online learning in the same international survey study (International Association of Universities, 2020) found. Barrett (2011) explains that teaching staff were trained in and used some pedagogies throughout their career which now needed to change and "...online educators have had to learn new ways of implementing and nurturing learning for their virtual student populations" (p. 20).

Kebritchi et al. (2017) discuss that interaction between the instructor and the learners in online classes is crucial to achieve learning outcomes. However, this is a significant concern due to the differences between online instruction and traditional classes. Mayes et al. (2011) discuss how overall course satisfaction is closely associated with the interaction patterns in online education. They also suggest a more student-centered approach to increase interaction. In this approach, the students can collaboratively take certain decisions regarding the course. The perceived lack of interaction could be partly attributed to reliance on visual cues and body language. Teaching staff may find it challenging to adjust their established teaching methods to conduct online courses (Fein \& Logan, 2003; Kebritchi et al., 2017).

Chang et al. (2014) found that perceptions of various roles involved in online teaching strongly correlate with the practices in those roles. Thus, professional development activities 
need to focus on skills perceived to be most essential by the online teaching faculty. The type of training provision is also considered important. Using online delivery for teachers' professional development activities is also discussed considered a solution to some critical issues by providing flexibility and accessibility (Nese et al., 2020).

Compton (2009), regarding some earlier studies, discusses that teacher training for online education needs to be delivered online to experience first-hand the community building process in online classes and the limitations and advantages of this medium. Stickler et al. (2020) also emphasize the role of experiential learning in gaining a better insight into the dynamics of online teaching.

\section{Training for Teaching Online}

Potential challenges and disadvantages of online education could be overcome or controlled, or better managed with proper training of teachers and students. Educational institutions attempted to train teachers to teach online, some with a limited understanding of the established practices based on research. Gold (2001) explicitly distinguished that the shift to online education is a complex process, and it requires specialized training in technical aspects of delivering quality educational materials to learners. Gold (2001) further expounds the importance of teachers having an authentic experience of online learning prior to online teaching. Otherwise, teachers replicate traditional teaching in online environment with some minor adjustments. Essentially, Gold (2001) focuses on a few vital factors, such as the need for proper pedagogical training for teachers to deliver quality educational materials and training to facilitate knowledge acquisition. Gold (2001) also discusses two sets of technological skills:

The first one is using technology to create and implement learning environments (i.e., online courses) for students. The second, the ability to instruct within the learning environment created - in other words, the facilitation of content to the student via the Web in an asynchronous format (p.36).

There have been a lot of research and review papers on what skills are essential for successful online teaching. It is clear that online education is different from face-to -face education. Therefore, there is a need to reconsider one's preferred teaching methodology and materials and adapt them according to this medium (Compton, 2009; Chang et al., 2014). As Kebritchi et al. (2017) express, “... there should be another way to look at online teaching approaches and online faculty preparation programs considering new strategies to aid in promoting better education for students" (p. 18). Studies based on various models and skillsets provide different solutions and suggestions to the issue of training.

In their international survey on faculty training for online education, the International Association of Universities (2020) found that about $80 \%$ of the respondents requested training for effective online teaching, whereas assessment, support to manage online classes, and security software were not considered significant.

In a study on professional development for online staff, Schmidt et al. (2016) found that the participants were provided with some training opportunities on using technology but lacked course design or effective pedagogical practices, which participants requested in their comments, 
and led to the following remark: "Since much existing training for online instructors focuses on technology, greater emphasis on course development and online pedagogy is important" (Summary section, para. 2).

Compton (2009) suggests a sequential three-level framework for professional development of online language teachers starting at novice level, proceeding to proficient and expert level, respectively. The three main areas in her suggested model include technology, pedagogy, and evaluation as key competencies to teach online effectively.

Fein and Logan (2003) consider using technology confidently as an essential skill for online teachers for successful teaching and the availability of IT support from specialists. According to Compton (2009), “...technological skills, relate to knowledge and ability to handle hardware and software issues" (p. 77). Technological skills are considered in three sequential levels, from novice to expert online teachers. Stickler et al. (2020) provide a detailed list of technical/technological tasks related to online courses from using software and networked computers to using social media for teaching purposes. As a result of their literature review, Kebritchi et al. (2017) emphasize the importance of training on technical skills to achieve success in online education. Koehler and Mishra (2005), however, warn about the hazard of training on technology in isolation and recommend technology training to be delivered in the context of pedagogy specific to the discipline.

Koehler and Mishra (2005) suggest that pedagogy is the driving force behind achieving change in education and technology is a tool to serve this purpose: "it is necessary to teach technology in contexts that honor the rich connections between technology, the subject-matter (content) and the means of teaching it (the pedagogy)" (p. 148). In support of this point, Kebritchi et al. (2017) suggest that training providers should include pedagogy to deliver practical online courses. As an example of pedagogical applications, Fein and Logan (2003) recommend adopting a "project-based approach". In this approach students collaborate on tasks to solve problems, and the teacher acts as a facilitator using various online interactive tools.

Stickler et al. (2020) consider being able to identifying differences between the requirements of traditional and online language teaching a critical skill. They further suggest in their findings that training on pedagogy for online language teachers is necessary, and elements of interaction, collaboration, and learner autonomy should be catered for in online education.

An essential element in any type of teaching and learning is interaction. The need for interaction is especially felt in online education, which provides different opportunities and challenges than a traditional classroom environment. Therefore, interacting with learners and facilitating group interactions among learners are considered important skills for online teachers. Many studies including Compton (2009), Chang (2014) and Stickler et al. (2020) highlighted the requirement of interaction. Compton (2009), in her three-level model of online teacher skills, comments on the importance of building a learning community through social interaction and how novice teachers should acquire the competencies related to the facilitation of this process.

Chang et al. (2014) also acknowledge the importance of facilitating the participation of students as an online teaching skill and recommend integrating this into professional 
development programs for teachers. Stickler et al. (2020) emphasize that successful online language teaching requires interaction opportunities facilitated by the instructor "...the tools used for communication, and interaction are crucial and teachers need to ensure that they develop the skills for using the affordances of the online medium and facilitating online socialization" (p. 139).

There are various types of training discussed in the literature on training to teach online. Schmidt et al. (2016) suggest using diverse options including formal workshops, informal discussions, and support groups. They also recommend short introductory training sessions, after which peer groups look into topics and expand on their knowledge. Peer learning sessions where teachers share their experiences were also found helpful among their respondents (Schmidt et al., 2016).

Compton (2009) notes that her framework for training is a continuum rather than isolated skills and mentions the importance of training and practice to move from novice to proficient and expert levels with possible integration into programs designed for training online language teachers. Chang et al. (2014) also highlight the importance of providing continuity in professional development with support in administrative and technical areas. Stickler et al. (2020) also recommend "systematic and ongoing teacher development opportunities focusing on developing both technological as well as pedagogical skills, which can be achieved through the inclusion of relevant hands-on activities, reflection, collaboration, and observations" (p. 141).

\section{Methods}

\section{Research Questions}

1. What are the participant teachers' and administrators' perceptions on the advantages and disadvantages of online education during the COVID 19 pandemic?

2. How does the teacher training process for online education work in each context?

3. What support is available after the initial training provision?

\section{Context and Participants}

This study was conducted at two leading higher educational institutions in the Sultanate of Oman during the outbreak of the COVID 19 pandemic. One part was carried out in the English Language Centre (ELC) at the University of Technology and Applied Sciences in Ibra, Oman and the other was conducted at the English Language and Literature Department (ELL) at Dhofar University in Salalah, Oman.

The ELC Ibra delivers the General Foundation Program (GFP), and the Post Foundation Program (PFP). The GFP consists of four levels, and the PFP provides four courses. The GFP delivers English skills required for learners' degree programs such as engineering, business, and Information Technology. The current study at ELC Ibra focused on GFP only. At ELC Ibra, four GFP level coordinators and three administrators participated in the study. The GFP coordinators were selected as representatives of the teaching staff for their respective levels. The administrators included the Head of Center, Head of English Language Programs and Head of Curriculum and Teaching Methods. All participants were full-time employees. 
ELL Dhofar delivers university requirement courses at five levels at the post-foundation level. These courses aim to develop various communicative skills in English language and academic study skills of the learners. ELL Dhofar also has department-specific courses, which are offered to BA in English Language students. The participants taught and managed both kinds of programs. ELL Dhofar participants consisted of two administrators with management roles, five coordinators of the university requirement English language courses, and an English Literature specialist. The teaching staff taught linguistics courses, literature courses, translation courses, and the university requirement courses. The participants were all full-time employees.

The participants at both institutes had varying levels of ELT experience and qualifications (see Table 1).

Table 1. Demographic profile of participants

\begin{tabular}{llcc}
\hline \multirow{2}{*}{ Demographic Values } & & ELC Ibra & ELL Dhofar \\
\hline Role & Management & 3 & 2 \\
& Teaching/Coordination & 4 & 6 \\
\hline \multirow{2}{*}{ Gender } & Male & 6 & 7 \\
& Female & 1 & 1 \\
\hline \multirow{2}{*}{ Highest Qualification } & Bachelor's & 0 & 0 \\
& Master's & 6 & 2 \\
& PhD & 1 & 6 \\
\hline
\end{tabular}

\section{Ethical Issues}

It was mandatory to obtain permission from the Research and Consultancy Committee, at ELC Ibra before conducting the study. The researchers completed an Ethical Approval Form to collect the data, for which the approval was given. Similarly, at ELL Dhofar, an official research application was made to the University Research Board, and permission was received prior to the commencement of the study.

Receiving the official approval to carry out the study, the researchers invited potential participants to hold semi-structured interviews. The procedure was relatively easy and convenient, as the researchers knew the respondents personally. This rapport with the respondents made the interview process much quicker and more effective than expected. The interview guides were distributed to the respondents in the invitation email. All interviews were audio recorded with consent and transcribed using Otter Voice Meeting Notes. Personal details and the positions of each respondent were anonymized during the transcription stage. The researchers tried to ensure confidentiality of data and anonymity as essential elements of research ethics. 


\section{Data Collection and Data Analysis}

The researchers used semi-structured interviews as the data collection tool in this study. The interviews provided detailed accounts of online teacher training needs and other focal areas of the research. The interview questions were adapted from an earlier study (Yapar, 2021) and consisted of two sets: one for the administrators/directors and the other for the teaching staff. These interview guides were checked for face and construct validity by a team of five Ph.D. holders in Education and English Language Teaching. The questions were asked to both groups to compare and contrast their perspectives and included the following areas: perceptions on online education, previous online education experience, and elements of the training program for online teaching. There were additional questions in the administrators' interview guide on the details of the training program, the decision-making process for training, and available support for online teaching staff.

\section{Validity and Reliability}

Gibbs (2007) suggests several qualitative reliability procedures such as checking interview transcripts for accuracy, consistency in coding the data, coordination between and among the researchers and cross-checking codes or intercoder agreement. In line with the reliability measurements, a constant comparative analysis was adopted. First, the researchers revisited the interview transcripts and the recorded interviews to ensure that the interview data were transcribed correctly in Otter Voice Meeting Notes. Any discrepancies between the audio files and automated transcripts were manually corrected. Confirmation of transcript accuracy was followed by the initial data coding under different themes, which were conducted by researchers separately for two data sets. Later, the codes and the content were reviewed jointly for accuracy. To reach a consensus on the final list of codes the researchers spent a considerable amount of time, reflection, and discussion. Hence, this coordination and interrelationship established inter-rater reliability on classifying data collected under different themes. This careful procedure resulted in the consistency and the reliability of the data coding in this study.

Gibbs (2007) suggests eight approaches to enhance the validity of the findings. The first of these, triangulation, refers to cross-examining various perspectives and different data collection sources to justify the findings of an investigation. Patton (2002) identifies numerous ways of triangulation in a research study to attain higher credibility for findings. This study consists of two types of respondents: administrative staff and teachers. The questions about advantages and disadvantages of online teaching, online teacher training, and the effectiveness of the training sessions were asked to both groups of respondents to compare their responses based on triangulation.

Creswell and Creswell (2018) also figure out rich, thick descriptions as another strategy to establish credibility of the findings by providing readers with detailed descriptions of the settings. The shared experience along with varying perspectives about the themes make findings more realistic and richer (Creswell \& Creswell, 2018). The current study collects data from both teachers and administrative staff. Hence, the researchers were able to elicit comparative perspectives on the same themes. This strategy also increased the validity of the research findings. 


\section{Results}

The findings from the interviews are categorized under three main themes, including the advantages and disadvantages of online education, training for teaching online, and available support.

\section{ELC - UTAS Results}

In the ELC Ibra interview data, there were a total of 20 mentions of advantages while disadvantages were mentioned 24 times. The advantages are depicted in Figure 1, where 'accessibility' recorded the highest score among all (25\%), followed by similar percentages $(15 \%)$ for 'new skills for teachers' and 'safety'. $10 \%$ of respondents perceived 'financial benefits', 'independent learning', and 'new skills for students' as advantages of online education. The item 'lower workload' was not mentioned at all in the interviews.

Figure 2 represents the disadvantages based on the interview data from ELC Ibra. Around $33 \%$ perceived 'lack of interaction' as the most important disadvantage of online education, followed by 'technical issues' (29\%). About 8\% mentioned 'cultural barriers', 'distractions', 'exam reliability', and 'teaching methods and pedagogy' as some other demerits of online education. However, only 4\% viewed 'affordability' as a drawback. The item 'materials' was not mentioned during the interviews.

The study explored the teacher training process also for online education. This process was investigated from different angles such as training needs identification, the efficiency of the training programs, feedback and evaluation of the training programs, and the support available in each context. Identification of training needs of teachers was an area specific to administration. Training on pedagogy was indicated as a top training need for teachers. However, training on online assessment was not mentioned among training needs. The administration coordinated with the Professional Development Committee to arrange training sessions and workshops targeting the identified training needs. Participating teaching staff were not consulted at this stage regarding their training needs. Interviews also revealed that administration collected feedback after the training sessions through questionnaires, verbal feedback, and dialogues with teachers. Whether the input was later implemented in any way was not evident from the interview data. Regarding the support available at the ELC, teachers commended the technical support provided by Moodle administrator at the Educational Technology Center (ETC).

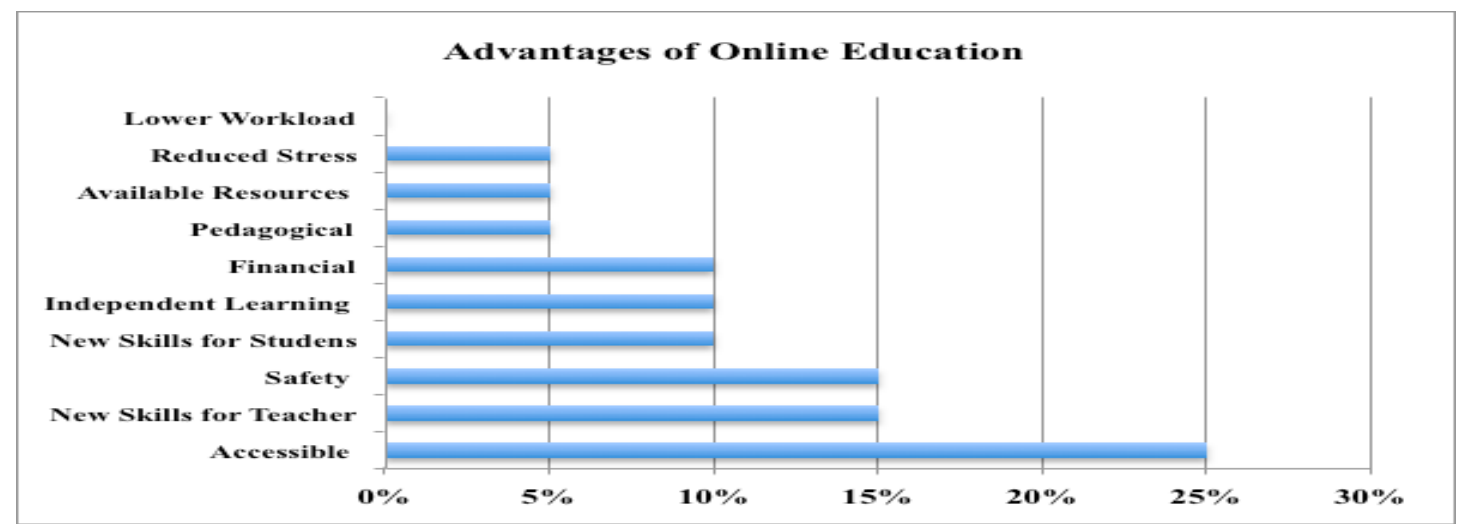

Figure 1.ELC Ibra Perspectives on Advantages of Online Education 
Arab World English Journal (AWEJ) 2nd Special Issue on Covid 19 Challenges January 2022

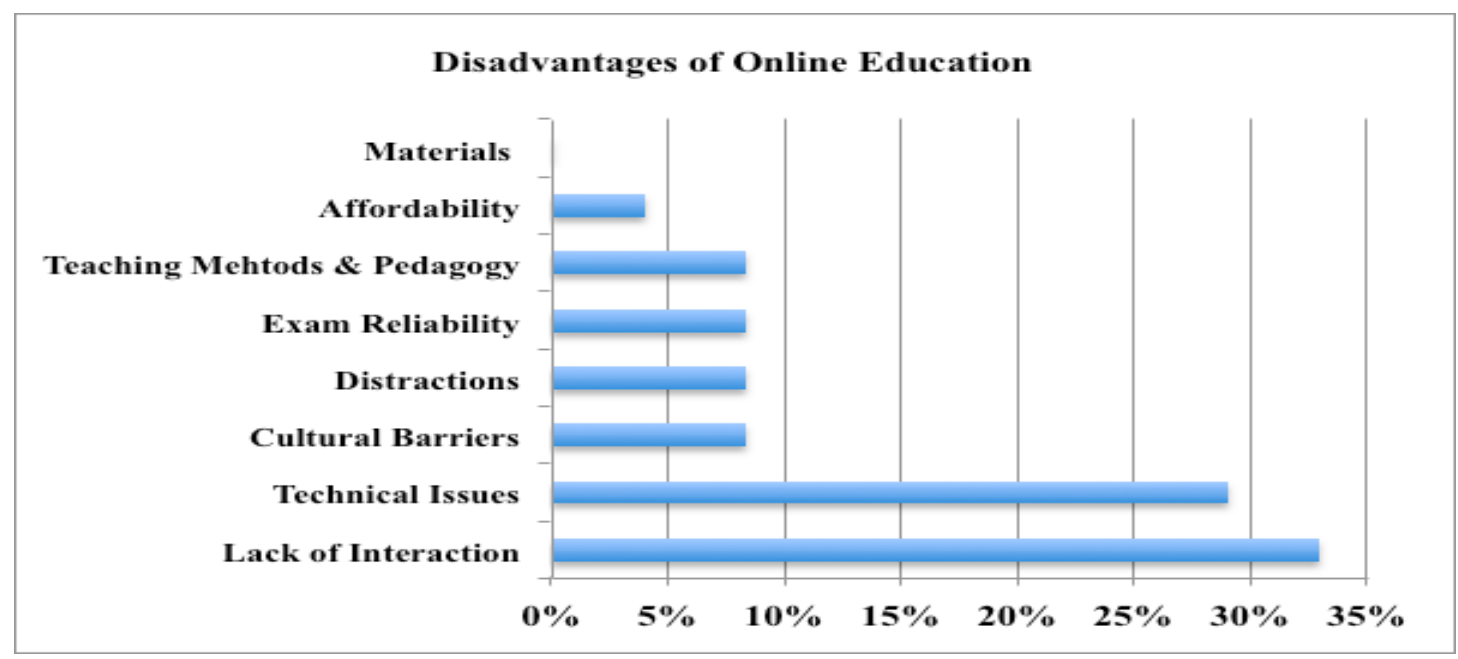

Figure 2. ELC Ibra Perspectives on Disadvantages of Online Education

\section{ELL Dhofar University Results}

In the ELL Dhofar interview data, there were a total of 25 mentions of advantages, compared to 36 mentions of disadvantages. The advantages mentioned in the interviews are demonstrated in Figure 3, where 'accessibility' had the highest score (28\%), followed by 'new skills for teachers' (16\%), and 'new skills for learners' (16\%). The item 'lower workload' which actually was not mentioned in the interviews.

In Figure 4, the disadvantages are demonstrated based on the interview data from DU ELL. The most frequently mentioned disadvantage was 'technical issues' (30.6\%), followed by 'exam reliability-academic integrity' (25\%), and 'lack of interaction' (11.1\%). The item 'materials' was not mentioned during the interviews.

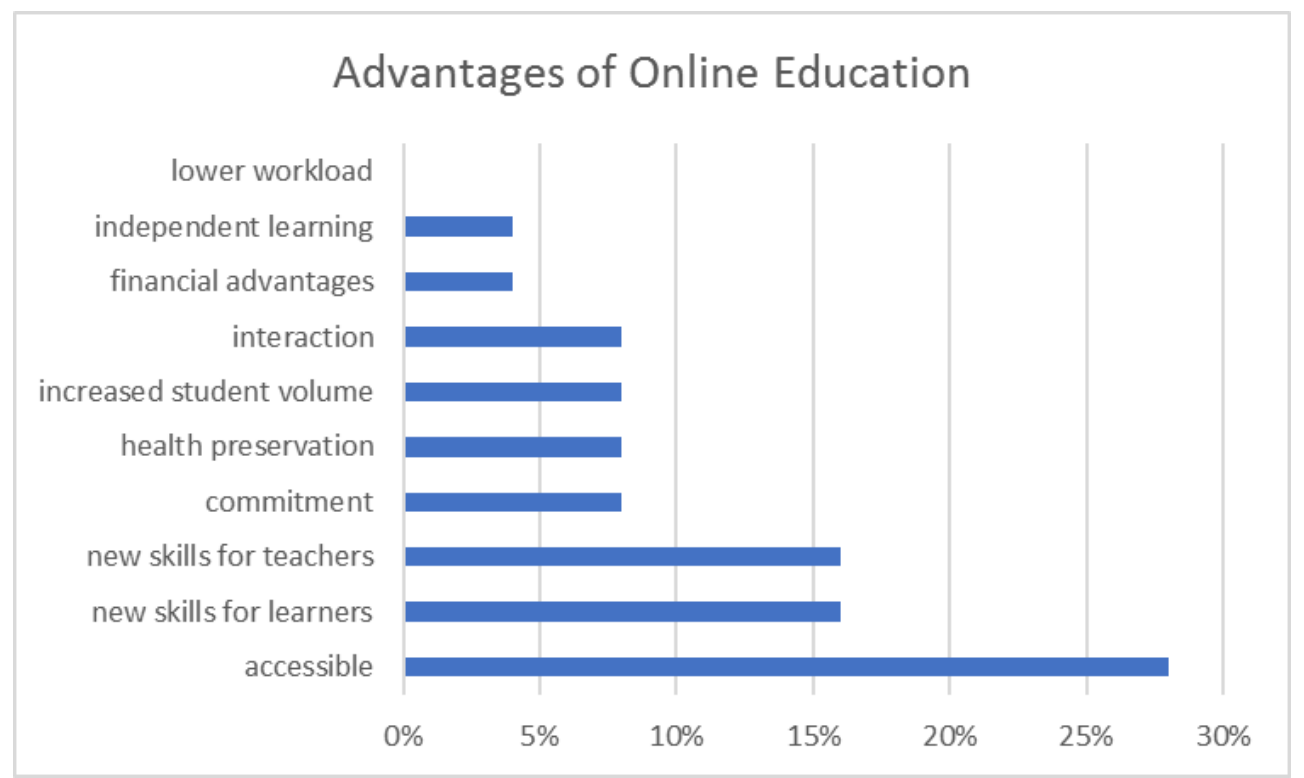

Figure 3. Advantages of Online Education from ELL Dhofar interview data 


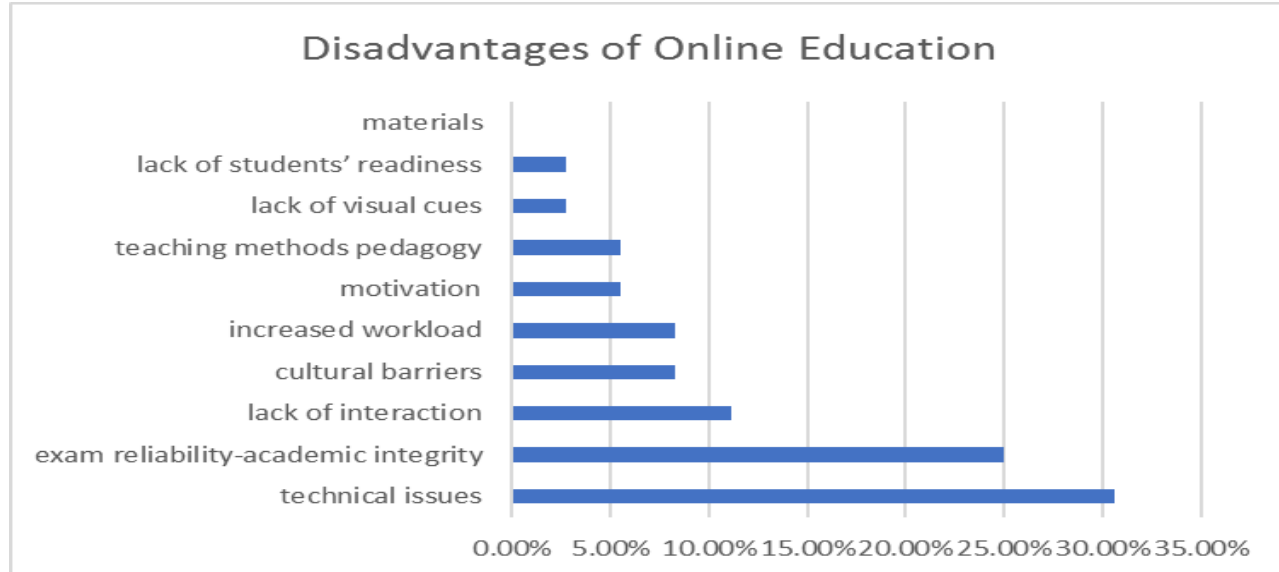

Figure 4. Disadvantages of Online Education from ELL Dhofar interview data

The comments on the training needs of faculty indicated the variety in participants' perspectives. 'Technical training needs' was mentioned repeatedly to refer to different functions of Moodle. On the other hand, pedagogical and assessment aspects of online education were also covered by several participants. To highlight the difference between different skill sets, one of the directors expressed "I think people need to differentiate between being able technically to go online and start the class and then teach and being an effective teacher online. These are two different things in my own opinion". In terms of training types, short and effective workshops were preferable to longer lecture-style sessions. Diversification of training sessions was also suggested for faculty with different skill levels.

Finally, there were two forms of support identified by the faculty. These were "focal points" and technical support from the Computing and Networking Center (CNC). The focal points were appointed by each college to support other colleagues in need. One of the challenges with this type of support was that these people also had teaching duties and other work-related commitments. Therefore, their availability was limited. Moreover, they were not specialists in online education or technical issues. Some participants suggested employing full-time specialists to offer online and on-site support to the faculty.

\section{Discussion}

The first research question focused on the perceptions of the participants on online education and was answered by the interview data on advantages and disadvantages. In both contexts, the number of mentions of disadvantages were more than the advantages. This implies that online teaching is considered more disadvantageous than traditional classroom teaching. For the participants, the online medium of teaching was not a preferred choice but a requirement of their institutions.

The next research question about the training process included several elements: decision making/planning and training needs. In terms of the decision making, participants in either organization were not involved in decision making or planning processes for their professional development activities to teach online. The senior management made those decisions and teachers were only participants in the provided training. Feedback was collected from participants following the training sessions, although there was no indication that the suggested 
changes in the feedback were implemented. However, including participants in decisions regarding their professional development can increase effectiveness (Scarpena et al., 2018; Schmidt et al., 2016). In terms of the decision processes related to language teacher training, a bottom-up approach is also recommended by Mann (2005), and is considered more effective (Rutherford, 2010; Stickler et al., 2020). Involving teachers in decisions regarding the content, priorities, pace, and delivery of their professional development is also recommended (Nese et al., 2020; Stickler et al., 2020).

Secondly, the training needs mentioned in the interviews focus more on technical training. Due to the technical problems they face, online teachers understandably have a more pressing need to resolve those. On the other hand, the lack of interaction was considered a disadvantage by many participants. However, pedagogical needs such as interaction in the online platforms, using technology for different pedagogical purposes, and building a learning community were not mentioned frequently in the interviews despite their coverage in the relevant literature. This is probably due to a lack of awareness and experience in the field of online education. In order to increase awareness of these issues, Compton (2009) suggests that online language teacher training programs provide differentiation for various responsibilities and expertise levels as well as online teaching practice at an early stage.

Course design was not discussed by participants in the interview data. However, the use of new technology certainly affects the instructional methods and the content that can be appropriately covered. Course learning outcomes, learning materials, tests, tasks, and assessments all need to be reconsidered in the light of the new technology and complement each other. This is an area that did not appear in the interview responses, probably due to a lack of awareness among the participants on the differences between face-to-face teaching and online teaching. Chang et al. (2014) suggest that course design should be provided as part of professional development for online education. Nese et al. (2020) recommend use of online learning as a delivery format to provide tailored and effective training on specific skills. Moreover, they claim professional development can increase "teacher acceptability", which eventually increases online learning effectiveness.

In the interview responses, participants expressed a preference for short and practical sessions rather than long and lecture-style ones. This is also confirmed by relevant studies. For example, Koehler and Mishra (2005) advocate for learning by design as it "appears to be an effective instructional technique to develop deeper understandings of the complex web of relationships between content, pedagogy and technology and the contexts in which they function" (p. 131).

Moreover, Schmidt et al. (2016) found that delivering small and focused training sessions for participants of similar discipline. Stickler et al. (2020) suggest that there is a relationship between professional development and student learning in established literature. The training sessions are suggested to be "hands-on" followed by practice of the newly acquired competencies and sharing of experiences in peer group reflection activities. Moreover, a combination of technical skills and pedagogical purposes should be covered at different skill levels. 
The final research question aimed to determine what support was made available in each context following the training sessions. Moving from face-to-face teaching to online education was a learning curve for most institutions including administrators and teaching staff. The most immediate form of support was peer support. This type of support is highly available as colleagues are accessible, approachable, and have similar practical experiences. Committee members were formally recognized for their role in supporting colleagues. However, informal discussions in the staff room also led to learning of using specific software or techniques on resolving motivation issues in classes. Stickler et al. (2020) suggest that organizing peer support in practical reflective workshops can result in successful collaborative practices and forming a community of practice.

To be successful in quality online education delivery, there is a particular need for continuous support. Berge (1998) contends that support from administration is necessary for successful implementation of online education and dealing with the challenges. Moreover, Chang et al. (2014) reassert that administrative support is essential especially in fulfilling training requirements. In both contexts in this study, there were committees formed bridging the communication gap between the management and the teaching staff. These committees had regular meetings to make recommendations based on the field experiences and feedback from colleagues. Whether the feedback was acted upon, and what particular administrative support was needed needs further exploration in a future study. Although peer support has some uses mentioned above, peers were not specialists in online education, nor had the full-time availability for their colleagues. Therefore, participants felt support from dedicated specialists could prove to be more valuable. This could be a practical step in demonstrating administrative support by the institutional leadership.

\section{Conclusion}

This paper explored the perceptions of a group of English Language Teachers and university administrators on online education during the Covid-19 era as well as the training process and support provided for the teachers. The study was carried out only in two academic institutions with a limited number of participants, and it should be expanded to a broader sample in various contexts for the future. However, the comparative nature of this study involving a public and a private university; foundation and post foundation levels; administrators and teaching staff helped identify similarities and differences between the two contexts. Moreover, the data were discussed in the light of established literature in this field which strengthened the reliability of findings and recommendations. The results and recommendations will be useful for institutions internationally that operate in similar contexts in their attempts to provide training and support for effective online education.

\section{About the Authors:}

Dr. Osman Erdem Yapar is an experienced educationalist who has worked in the UK, Turkey, and Oman teaching English to adult learners in various higher education institutions. His research interests include online learning, teacher training, moral values education, intercultural communication, and English language teaching. He has publications in these fields, which are accessible under his ResearchGate profile. ORCID: https://orcid.org/0000-0002-3400-083X 
Arab World English Journal (AWEJ) 2nd Special Issue on Covid 19 Challenges January 2022

Chinthana Sandaruwan Dayananda is an English language educator with over a decade of experience in a variety of contexts in Sri Lanka and Oman. He holds an MA in Linguistics from Sri Lanka and a CELTA certificate. He is currently based at University of Technology \& Applied Sciences, Oman. His research interests are learner autonomy, distance education, and communication skills. ORCID: https://orcid.org/0000-0003-2645-9613

\section{References}

Ally, M. (2008). Foundations of educational theory for online learning. In T. Anderson (Ed.) The theory and practice of online learning (pp. 15-44). Edmonton: AU Press.

Andreas, S. (2020). The impact of COVID-19 on education: Insights from education at a glance 2020. OECD.

Assunção Flores, M., \& Gago, M. (2020). Teacher education in times of COVID-19 pandemic in Portugal: National, institutional and pedagogical responses. Journal of Education for Teaching, 46, 507 - 516.

Barrett, B. G. (2011). Virtual teaching and strategies: Transitioning from teaching traditional classes to online classes. Contemporary Issues in Education Research, 3, 17-20.

Berge, Z. (1998). Barriers to online teaching in post-secondary institutions: Can policy changes fix it?. Online Journal of Distance Learning Administration. 1 (2), pp. 1-13.

Chang, C., Shen, H., \& Liu, E.Z. (2014). University faculty's perspectives on the roles of einstructors and their online instruction practice. The International Review of Research in Open and Distributed Learning, 15, 72-92.

Chen, S. T. (2012). Perceptions of online TESOL teacher education: Strengths, weaknesses, characteristics, and effective components (Doctoral dissertation). Proquest Dissertations and Theses. (UMI 3513737)

Compton, L. K. (2009). Preparing language teachers to teach language online: A look at skills, roles, and responsibilities. Computer Assisted Language Learning, 22(1), 73-99. doi:10.1080/09588220802613831

Creswell, J., \& Creswell, D. (2018). Research design. qualitative, quantitative \& mixed methods approaches. $\left(5^{\text {th }} \mathrm{Ed}\right)$. Sage.

Faulkner, C. A., Faulkner, S., Cutsinger, M. M., King, D. S., Bishop, S. M., \& Long, J. (2018). Evaluation of online classes using the seven principles of effective teaching. American International Journal of Social Science, 7(4). doi:10.30845/aijss.v7n4p1

Fein, A., \& Logan, M.C. (2003). Preparing instructors for online instruction. New Directions for Adult and Continuing Education, 45-55.

Gibbs, G. (2007). Analyzing qualitative data (Book 6 of The SAGE Qualitative Research Kit). London: Sage.

Gold, S. (2001). A constructivist approach to online training for online teachers. JALN, 5(1),3557.

Harton, H. C., Aladia, S., \& Gordon, A. (2019). Faculty and student perceptions of cheating in online vs. traditional classes. Online Journal of Distance Learning Administration, 22.

International Association of Universities (2020). Regional/National perspectives on the impact of COVID-19 on higher education. International Association of Universities.

Jacobs, P. (2014). Engaging students in online courses. Research in Higher Education Journal, 26. 
Arab World English Journal (AWEJ) 2nd Special Issue on Covid 19 Challenges January 2022

Kebritchi, M., Lipschuetz, A. M., \& Santiague, L. (2017). Issues and challenges for teaching successful online courses in higher education. Journal of Educational Technology Systems, 46, 29 - 4.

Koehler, M.J., \& Mishra, P. (2005). What happens when teachers design educational technology? The development of technological pedagogical content knowledge. Journal of Educational Computing Research, 32, 131 - 152.

Mann, S. (2005). The language teacher's development. Language Teaching, 38(3), 103-118. https://doi.org/10.1017/S0261444805002867

Marinoni, G., Land, H., \& Jensen, T. (2020). The impact of COVID-19 on higher education around the world. International Association of Universities, France.

Mayes, R., Lueback, J., Ku, H., Korkmaz, O., \& Akarasriwonr, C. (2011). Themes and strategies for transformative online instruction: A review of literature and practice. The Quarterly Review of Distance Education, 12.

Nese, R. N., Meng, P., Breiner, S., Chaparro, E., \& Algozzine, R. (2020). Using stakeholder feedback to improve online professional development opportunities. Journal of Research on Technology in Education, 52(2), 148-162. doi:10.1080/15391523.2020.1726233

Oyadiran, W. O., Omoare, A. M., Owoyemi, A. M., Adejobi, A. O., \& Fasasi, R. B. (2020). Prospects and limitations of e-learning application in private tertiary institutions amidst COVID-19 lockdown in Nigeria. Heliyon 6.

Oyedotun, T. D. (2020). Sudden change of pedagogy in education driven by COVID-19: Perspectives and evaluation from a developing country. Research in Globalization 2.

Patton, M. Q. (2002). Qualitative research and evaluation methods (3rd ed.). Thousand Oaks, CA: Sage.

Rutherford, C. (2010). Facebook as a source of informal teacher professional development. Education 3-13, 16.

Scarpena, K., Riley, M., \& Keathley, M. (2018). Creating successful professional development activities for online faculty: A reorganized framework. Online Journal of Distance Learning Administration, 21(1), 1-8.

Schmidt, S., Hodge, E. M., \& Tschida, C. M. (2016). How faculty learn to teach online: What administrators need to know. Online Journal of Distance Learning Administration, 19 (1).

Stickler, U., Hampel, R., \& Emke, M. (2020). A developmental framework for online language teaching skills. Australian Journal of Applied Linguistics, 3(1), 133-151. doi:10.29140/ajal.v3n1.271

Toquero, C.M. (2020). Challenges and opportunities for higher education amid the COVID-19 pandemic: The Philippine context. Pedagogical Research, 5. https://doi.org/10.29333/pr/7947

White, C. (2003). Language learning in distance education. Cambridge: Cambridge University Press.

Yapar, O. E. (2021). Teacher training for distance education: A case study on ELT faculty's perceptions in three Turkish universities. In A. Kabadayi (Ed.), Current academic studies in educational sciences (pp. 26-45). Livre de Lyon. https://academicworks.livredelyon.com/edu_sci/60/

We confirm that the manuscript is our original work and a result of a joint study we conducted. Dr. Osman Erdem Yapar and Chinthana Sandaruwan Dayananda 